\title{
Is Hyperbaric Oxygen Therapy
}

Effective for Traumatic Brain Injury?

A Rapid Evidence Assessment of the

Literature and Recommendations for

the Field

\author{
Cindy Crawford, BA; Lynn Teo, MAOM, MS; EunMee Yang, MS; Caitlin Isbister, MS;
}

Kevin Berry, MD

\begin{abstract}
Objective: This systematic review examines the efficacy of hyperbaric oxygen $\left(\mathrm{HBO}_{2}\right)$ for traumatic brain injury (TBI) to make evidence-based recommendations for its application and future research. Methods: A comprehensive search was conducted to identify studies through 2014. Methodological quality was assessed and synthesis and interpretation of relevant data was performed. Results: Twelve randomized trials were included. All mild TBI studies demonstrated minimal bias and no statistically significant differences between $\mathrm{HBO}_{2}$ and sham arms. Statistically significant improvement occurred over time within both groups. Moderate-to-severe TBI studies were of mixed quality, with majority of results favoring $\mathrm{HBO}_{2}$ compared with "standard care." The placebo analysis conducted was limited by lack of details. Conclusions: For mild TBI, results indicate $\mathrm{HBO}_{2}$ is no better than sham treatment. Improvements within both $\mathrm{HBO}_{2}$ and sham groups cannot be ignored. For acute treatment of moderate-to-severe TBI, although methodology appears flawed across some studies, because of the complexity of brain injury, $\mathrm{HBO}_{2}$ may be beneficial as a relatively safe adjunctive therapy if feasible. Further research should be considered to resolve the controversy surrounding this field, but only if methodological flaws are avoided and bias minimized. Key words: byperbaric oxygen therapy, placebo, sham, systematic reviewe, traumatic brain injury
\end{abstract}

\section{Author Affiliation: Samueli Institute, Alexandria, Virginia.}

The authors would like to acknowledge the Internal and External Steering Committee who contributed to the project. The Internal Steering Committee members were Kevin Berry, MD, Cindy Craweford, BA, Wayne B. Jonas, MD, John A. Ives, PhD, Joan Walter, JD (Samueli Institute); LTC Austin Chhoeu, USARMY MEDCOM USAMMDA, and Kyle Martin, Universal Consulting Services, Inc., Deputy Program Manager, Hyperbaric Oxygen Research Program.

The External Steering Committee and subject matter experts were Allene Creacy, Hyperbaric Healing Centers; Richard Ellenbogen, PhD, Department of Neurological Surgery, University of Washington; Irving Kirsch, PhD, Harvard Medical School; Saafan Malik, MD, Defense and Veterans Brain Injury Center, Defense Centers of Excellence for Psychological Health and Traumatic Brain Injury; Regina McGlinchey, PbD, VA Boston Healthcare System, Harvard Medical School; Richard Moon, MD, Duke University Medical Center; Douglas Smith, MD, University of Pennsylvania; Eric Schoomaker, MD, PhD, Department of Military o Emergency Medicine, Uniformed Services University. In addition the authors would also like to acknowledge Ms Viviane Enslein for her administrative and technical support throughout this project.

The Hyperbaric Oxygen Research Program, Army Medical Research and Materiel Command, funded this project through contract W911QY-14-P-0187 administered by the US Army Medical Research Acquisition Activity. The project was conducted by Samueli Institute independent of the funder. This report does not necessarily reflect the opinions or policies of the US Army or any other federal agency. No official endorsement is implied and none should be inferred. Although this article was reviewed and approved for release by Department of Army officials, the manuscript was written and prepared by Samueli Institute. The diverse stakeholders making up the steering committee and subject matter experts contributed to the systematic review protocol development and provided input throughout all phases of the project. Samueli Institute conducted the systematic review independent of the funder, steering committee, and empaneled experts for the purpose of identifying, minimizing, and control ling bias. The recommendations set forth in this report were made collectively by a working group that included the members of the steering committee, empaneled subject matter experts, and Samueli Institute staff during an expert roundtable meeting. The working group was tasked to evaluate for research gaps and to make recommendations for the future based on the systematic revieze.

This is an open-access article distributed under the terms of the Creative Commons Attribution-Non Commercial-No Derivatives License 4.0 (CCBY-NC-ND), where it is permissible to download and share the work provided it is properly cited. The work cannot be changed in any way or used commercially without permission from the journal.

Supplemental digital contents are available for this article. Direct URL citations appear in the printed text and are provided in the HTML and PDF versions of this article on the journal's Web site (wrerw.headtraumahab.com).

The authors declare no conflicts of interest.

Corresponding Author: Cindy Crazeford, BA, Samueli Institute, 1737 King St, Ste 600, Alexandria, VA 22314 (ccraveford@siib.org).

DOI: 10.1097/HTR.0000000000000256 
$\mathrm{H}$ YPERBARIC OXYGEN $\left(\mathrm{HBO}_{2}\right)$ has been proposed as an adjunctive therapy for traumatic brain injury (TBI). ${ }^{1}$ Reports from the 1960 s claimed improvement for patients with TBI undergoing $\mathrm{HBO}_{2}$; however, much of the clinical trial work then and now shows mixed results and the field remains controversial. ${ }^{1-3}$ Potential adverse events of $\mathrm{HBO}_{2}$, such as barotrauma and oxygen poisoning, and the clinical significance of these risks versus benefits are not yet fully understood. ${ }^{2,3} \mathrm{HBO}_{2}$ treatment for TBI has not been cleared or approved by the US Food and Drug Administration. ${ }^{4,5}$ There remains a lack of solid clinical evidence supporting the standard use of $\mathrm{HBO}_{2}$ for TBI.

Appropriate and effective treatments for patients suffering from the consequences of TBI remain unknown to date. With the increasing rate of reported TBI cases, and our soldiers returning home from war, effective treatments are imminently needed. The purpose of this systematic review is to provide an independent, objective, and transparent analysis of the research conducted to date exploring the evidence base for $\mathrm{HBO}_{2}$ as a therapeutic option for TBI. Specifically, this review (1) examines the quantity and quality of the research on $\mathrm{HBO}_{2}$ for TBI; (2) provides a concise understanding as to the safety, dosing variations, and efficacy of this intervention, as it is currently reported in the literature; (3) compares the differences noted across studies and gaps that currently exist in the research; (4) explores the use of sham and placebo in these randomized controlled trials (RCTs) to the extent that data are available for analysis; and (5) draws conclusions upon which recommendations can be made concerning next steps for the field of study.

\section{METHODS}

Concepts and definitions were clearly defined and agreed upon by a diverse steering committee (SC) and subject matter experts (SMEs) for both TBI and $\mathrm{HBO}_{2}$ therapy. ${ }^{6-8}$ The authors considered all literature looking across the spectrum of TBI sequelae from acute to chronic effects and from mild-to-severe TBI, both in military and civilian populations. Although the definition for TBI seems intuitively correct for moderate-to-severe TBI, it is significantly nuanced for mild TBI (mTBI). Because of the entanglement of symptoms and comorbidity between and within TBI, patients with posttraumatic stress disorder (PTSD) were not excluded as a population from the review.

\section{Study eligibility criteria}

Studies were included if they met the following criteria: (1) peer-reviewed study designs presented in the English language; (2) involving subjects suffering from the consequences of TBI in both military and civilian populations; and (3) $\mathrm{HBO}_{2}$ is being used as the intervention without preexisting conditions. All clinical outcomes, as well as types of control/comparators, were considered for inclusion to ensure capturing all studies relevant to the research question.

\section{Data sources and search strategy}

PubMed, CINAHL, PsycInfo, and Cochrane, as well as the Database of Randomized Controlled Trials in Hyperbaric Medicine, were searched from their database inception through December 2014 using the following search terms in PubMed and adapted as necessary in other databases: brain injuries or head injuries or craniocerebral trauma AND hyperbaric oxygenation or "hyperbaric oxygen therapy" or "hyperbaric oxygen*" or "hyperbaric therap"” or $\mathrm{HBO}$ or $\mathrm{HBO}_{2}$ or HBOT. In December 2014, an updated search was conducted and the additional search terms were included to ensure any entanglement with PTSD was captured in the review: "stress-disorders, post-traumatic" and "PTSD."

All searches were restricted to the peer-reviewed, English language studies involving human subjects.

\section{Study selection}

Two investigators independently screened titles and abstracts of the citations yielded from the literature search using the predefined study eligibility criteria. Interrater reliability as measured by Cohen's $\kappa^{9}$ was more than 0.90 throughout the screening phase.

\section{Quality assessment and data extraction for RCTs}

Methodological quality was independently assessed by 3 reviewers in duplicate using the Scottish Intercollegiate Guidelines Network Checklist for RCTs (SIGN 50). ${ }^{10}$ External and model validity were assessed using Samueli Institute's External Validity Assessment Tool (EVAT, Alexandria, Virginia). ${ }^{11}$ Descriptive data were also extracted and study designs other than RCTs were qualitatively described.

\section{Placebo analysis}

When available, information about the sham or control arm for each study was abstracted for placebo analysis as predefined attributes by the SC and SMEs. Parameters included expectation, conditioning, and social learning attributes.

\section{Outcome categorization}

Outcome assessment tools for included RCT studies were obtained. These tools were grouped into higher order categorization relevant to TBI and examined using the Common Data Element Project's classification of outcomes. ${ }^{12}$ 


\section{Data synthesis and analysis}

Meta-analysis was not performed because of lack of data available. The authors instead synthesized the evidence at the outcome level to (1) determine the confidence in the estimate of the effect; (2) assign a safety grade; and (3) provide an overall recommendation concerning the benefit/risk for the intervention based solely on the evidence being presented through an expert roundtable convening with the diverse SC and SMEs. ${ }^{13-16}$

\section{RESULTS}

\section{Study selection}

The initial database search yielded 393 distinct citations. An additional 2 eligible clinical trials, published after August 2014, were also included. Twelve unique RCTs, published in 16 reports, met the inclusion criteria (see Figure 1). Of these studies, $4 \mathrm{RCTs}^{17-23}$ involved mTBI populations suffering persistent symptoms over many months; 7 RCTs ${ }^{24-31}$ involved moderate-tosevere TBI populations treated acutely; and 1 article ${ }^{32}$ did not clearly define the severity of the TBI. (See Supplemental Digital Content A, available at: http: //links.lww.com/JHTR/A182.) An additional 27 nonRCT studies met the eligibility criteria and are described in Supplemental Digital Content B (available at: http://links.lww.com/JHTR/A183). ${ }^{33-59}$

\section{Quality assessment and risk of bias for included RCT studies}

Eight of the included RCTs were rated as acceptable $(+)^{17-23,25-27,29,31}$ and 4 were rated as low (0) methodological quality according to SIGN 50 criteria. $24,28,30,32$ (See Supplemental Digital Content C, available at: http://links.lww.com/JHTR/A184.) According to EVAT criteria, recruitment was predominately adequately covered, indicating that the majority of studies identified the source population and described recruitment methods. Participation was largely well covered, indicating study participants seemed representative of the source population. Model validity was mainly poorly addressed, indicating the manner by which the patients were treated in the studies was not described well enough to understand whether they are representative of the care model (staff, processes, facility, equipment, other resources) as they are in practice. (See Supplemental Digital Content D, available at: http://links.lww.com/JHTR/A185.)

When considering model validity, there was a wide dispersion in the staff conducting $\mathrm{HBO}_{2}$ treatments: an attending physician in 1 study $^{24}$; chamber technicians, study coordinators, and supervising physicians in a second study ${ }^{21}$; and a research crew (crew chief, chamber operator, inside attendant and medical monitor) in a third study. ${ }^{20,60}$ The specific type of researcher was not noted in the remaining 9 studies. For clinical setting, 7 studies were carried out at a hospital, ${ }^{21,25,27-32}$ one of which was a multisite study conducted at 4 military hospitals. ${ }^{21}$ Additional sites included a naval medicine operational training center, ${ }^{17,18}$ the US Air Force School of Aerospace Medicine, ${ }^{19,20}$ and a hyperbaric institute and research unit of a medical center. ${ }^{23}$ Two studies did not describe the study location. ${ }^{24,26}$ Ten of the 12 studies included details of equipment used to some extent; this mostly entailed describing the type of $\mathrm{HBO}_{2}$ chamber used. Five studies used multiplace, ${ }^{17-22,26,29,60}$ and 3 used monoplace chambers. ${ }^{25,30,32}$ An additional study placed some subjects in a multiplace chamber and others in a monoplace chamber. ${ }^{28}$ No studies compared outcome changes between a monoplace and a multiplace chamber or described in detail the environment within the chambers.

\section{Characteristics of mTBI studies}

Four studies, involving 250 participants, investigated the use of $\mathrm{HBO}_{2}$ for those suffering the consequences of mTBI. ${ }^{17-23}$ All 4 studies received a SIGN 50 score of acceptable $(+)$. Three of these studies were supported by the Department of Defense, involved military populations and compared $\mathrm{HBO}_{2}$ to a type of sham. ${ }^{17-22}$ The final study was a nonmilitary crossover study with a 2-month washout period. ${ }^{23}$ These studies involved various dosages in terms of exposure time to $\mathrm{HBO}_{2}$, with 30 to 40 sessions ranging from 60 to 117 minutes, over 8 to 10 weeks, and pressure ranging from 1.5 to 2.4 ATA (atmospheres absolute).

The types of sham arms differed in terms of pressure and oxygen levels. The first study administered 10.5\% oxygen at 2.0 ATA as the sham. ${ }^{17,18,22}$ The second study administered $21 \%$ oxygen (the same concentration as room air) at 1.3 ATA with a slow drift to 1.2 ATA. ${ }^{19,20}$ The third study administered $21 \%$ oxygen at 1.2 ATA. ${ }^{21}$ Two of these studies were 3 -armed trials. One study ${ }^{21}$ compared $\mathrm{HBO}_{2}$ plus "TBI-care" to sham plus "TBIcare" and "TBI-care" only. The other study" 17,18,22 exposed all groups to 2.0 ATA, but inspired oxygen was varied $(100 \%, 75 \%$, and $10.5 \%)$ to represent the tissue partial pressure of oxygen equivalent to the inspiration of $100 \%$ oxygen at each of $2.0,1.5$, and 1.0 ATA, respectively.

All mTBI studies assessed cognitive performance; 3 assessed psychological outcomes and 2 assessed postconcussive symptom severity. ${ }^{17,18,21,22}$ Overall these studies showed no statistically significant results between groups for any of these outcomes. However, there were some statistically significant within-group 

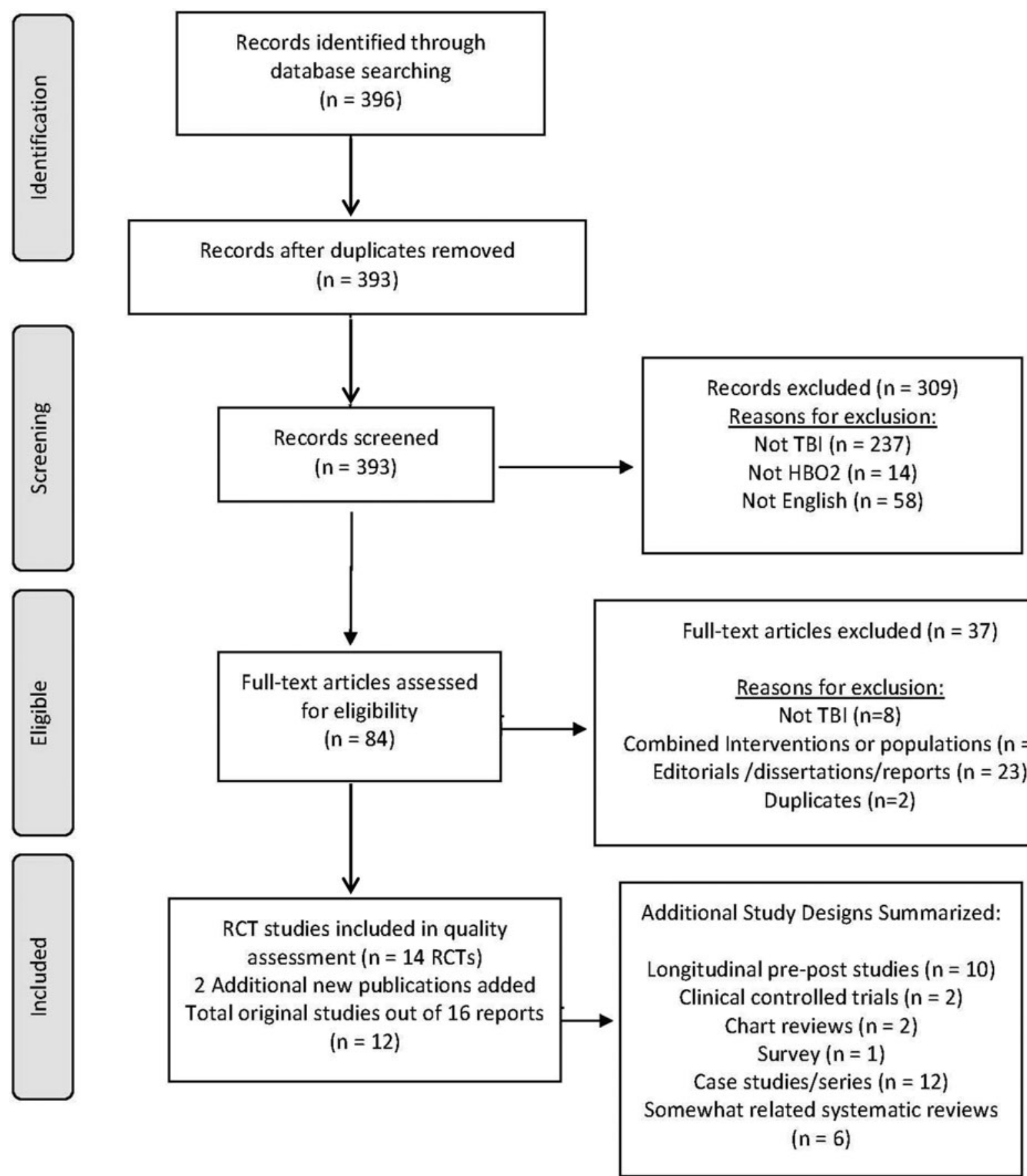

Figure 1. PRISMA flow diagram.

improvements within both $\mathrm{HBO}_{2}$ and sham groups across all relevant outcomes ${ }^{17-22}$ and both groups in the crossover study for cognitive performance. ${ }^{23}$ In one study, both $\mathrm{HBO}_{2}$ and sham groups improved for cognition and postconcussion symptom severity whereas the "TBIcare" only group worsened or stayed the same respectively. ${ }^{21}$ (See Supplemental Digital Content A, available at: http://links.lww.com/JHTR/A182.)

\section{mTBI reported adverse events}

Adverse events were categorized into 4 categories: ear problems, pulmonary complications, other minor, and other serious adverse events. Three of the $4 \mathrm{mTBI}$ studies describe adverse events ${ }^{19-21,23}$ whereas the remaining study did not mention adverse events. ${ }^{17,18,22}$ All 3 studies describe minor ear problems including barotrauma and ear pain. Two studies reported minor adverse events: nausea, sinus squeeze and sinus pain, 
claustrophobia, headache, musculoskeletal chest pain, latex allergy, tooth pain, and transient worsening of myopia. Pulmonary complications and serious adverse events were not reported. (See Supplemental Digital Content A, available at: http://links.lww.com/JHTR/ A182.)

\section{Characteristics of moderate-to-severe TBI studies}

Seven studies, involving 486 participants, investigated the use of $\mathrm{HBO}_{2}$ for those who had suffered moderateto-severe TBI and were being treated acutely. Four of these studies received a SIGN 50 score of acceptable $(+)^{25-27,29,31}$ and 3 were rated low (0) quality..$^{24,28,32}$ The $\mathrm{HBO}_{2}$ dosages for these studies involved a large range with 3 to 84 sessions, ranging from 40 to 120 minutes and over a period of 3 to 52 days. All studies used 100\% inspired oxygen and varied pressure with a range of 1.5 to 2.5 ATA.

One study compared $\mathrm{HBO}_{2}$ with no $\mathrm{HBO}_{2}$ treatment. ${ }^{26}$ Six other studies compared $\mathrm{HBO}_{2}$ with various forms of "standard care,"24,25,27-29,31,32 one of which was a 3 -armed study comparing $\mathrm{HBO}_{2}$ with "standard care" to normobaric hyperoxia. ${ }^{28}$ These studies were conducted over nearly a 40-year time span, and what was referred to as standard of care was inconsistent across the studies. None of the studies fully described the standard neurotrauma care in enough detail to compare the control arms across the studies.

Four studies involved outcome measures of consciousness $24,26,27,29,31$; 5 utilized the Glasgow Outcomes Scale (GOS) and/or measures of mortality ${ }^{24-27,31}$; and 2 involved intracranial pressure (ICP). ${ }^{25,28}$ In all 3 acceptable $(+)$ quality studies reporting on consciousness, the $\mathrm{HBO}_{2}$ groups experienced statistically significant better recovery compared with "standard care" $(n=2)$ and no $\mathrm{HBO}_{2}$ treatment $(n=1)$. The low (0) quality study found no statistically significant difference between groups overall. Results for the 3 acceptable $(+)$ quality studies reporting on the GOS and/or mortality conflicted: in 2 studies, the $\mathrm{HBO}_{2}$ groups showed statistically significant better scores versus "standard care", ${ }^{25,27}$ whereas the third study found no statistically significant differences between the $\mathrm{HBO}_{2}$ and no $\mathrm{HBO}_{2}$ groups overall. ${ }^{26}$ Both low (0) quality studies reporting on mortality rate found no statistically significant differences between $\mathrm{HBO}_{2}$ and "standard care" groups. ${ }^{24,30}$ Two studies measured ICP: the acceptable $(+)$ quality study reported no statistically significant difference between the $\mathrm{HBO}_{2}$ and "standard care" groups, ${ }^{25}$ whereas the low (0) quality study found ICP measurements significantly lower after each treatment in the $\mathrm{HBO}_{2}$ group compared with the "standard care" group. ${ }^{28}$ (See Supplemental Digital Content A, available at: http://links.lww.com/JHTR/A182.)

\section{Moderate-to-severe TBI reported adverse events}

Three of the 7 included studies involving moderateto-severe TBI populations describe adverse events, ${ }^{24-26}$ whereas the remaining 4 do not. ${ }^{27-31}$ These reports describe various ear problems including severe ear pain (resolved by tympanostomy) and hemotympanum; 2 describe pulmonary adverse events; and 2 report the occurrence of seizures. (See Supplemental Digital Content A, available at: http://links.lww.com/JHTR/A182.)

\section{Study in which TBI severity not described}

One study, in which severity was not described, was a low (0) quality study comparing $\mathrm{HBO}_{2}$ with a "standard medication" for 320 patients with postbrain neural injury. ${ }^{32}$ The $\mathrm{HBO}_{2}$ group was exposed to 0.1 megapascal (MPa) pressure, nearly equivalent to 1.0 ATA, while inspiring $96 \%$ oxygen. The authors did not report on or mention adverse events nor did they report on any outcomes relevant to this review.

\section{Placebo analysis}

Placebo might explain the paucity of between-group and the preponderance of within-group differences (improvements) between $\mathrm{HBO}_{2}$ and sham arms in the mild TBI review group studies. Placebo effects are context sensitive, dependent on expectancy, conditioning, and social learning. ${ }^{61}$ The placebo analysis was limited by the lack of details describing the sham or control arms of the studies (see Table 1).

The majority of studies report that informed consent was obtained from the patient or family member; however, only one study details the informed consent process. ${ }^{23}$ The description of the therapeutic intervention and sham during informed consent process can influence expectancy and meaning for the patient and affect the results of the study. ${ }^{62}$ Although the setting/patient experience and study location was reported in almost all studies, the full description was missing preventing context analysis. Studies reported whether a multiplace chamber or monochamber was used but did not describe the environment either inside or outside the chambers or whether patients studied in multiplace chambers were alone or with others (attendants or patients). The social experience or encounter is not discussed in these studies. The characteristics of the researcher/practitioner and their credentialing (believability), relationship between the research team and patient, and instructions given to the patient are not reported on in the majority of the studies. The human interaction element was not described in any of these studies. Only 2 studies described instructions given to subjects. ${ }^{17,18,22,23}$ None of the studies stated that expectation of the patient, attendant, or researcher 
TABLE 1 Placebo analysis of essential components for reporting

\begin{tabular}{|lcc|}
\hline & $\begin{array}{c}\text { Reported } \\
\boldsymbol{n}(\%)\end{array}$ & $\begin{array}{c}\text { Not reported } \\
\boldsymbol{n} \text { (\%) }\end{array}$ \\
\hline Informed consent & $8(66.7)$ & $4(33.3)$ \\
Setting/participant experience & $11(91.7)$ & $1(8.3)$ \\
Multichamber & 5 & \\
Monochamber & 3 & \\
Both multi- and monochamber & 1 & \\
Unclear & 2 & $3(25.0)$ \\
Study location & $9(75.0)$ & $9(75.0)$ \\
Placebo effect & $3(25.0)$ & $9(75.0)$ \\
Characteristics of researcher/practitioner & $3(25.0)$ & $10(83.3)$ \\
Relationship between researcher and subject & $2(16.7)$ & $3(25.0)$ \\
Follow-up & $9(75.0)$ & $7(58.3)$ \\
Reason for control/comparator & $5(41.7)$ & $6(50.0)$ \\
Blinding & $6(50.0)$ & $6(50.0)$ \\
Compliance & $6(50.0)$ & $12(100.0)$ \\
Expectancy & $0(0.0)$ & $10(83.3)$ \\
Instructions to patients during time within chamber & $2(16.7)$ & \\
\hline
\end{tabular}

was predetermined in the study's method or measured during the encounter.

Eight of the 12 studies conducted follow-up on specific outcome measures; 6 studies report whether blinding took place, however only 2 describe this procedure and state only that blinding was successfully carried out. One of these studies followed up with participants by asking whether they thought they participated in the $\mathrm{HBO}_{2}$ or sham arm. ${ }^{21}$ Compliance measures were reported in 6 of the studies, the majority of which simply reported subject dropout percentages. Patients dropped out because of scheduling conflicts, $\mathrm{HBO}_{2}$-related adverse events, medical issues, or incurring an additional mTBI injury. Fewer than half of the studies described the reason for selecting specific attributes in the control/comparator arm. Two studies failed to describe the comparator arms in any detail. 24,30

Three of the 12 studies concluded their results are likely due to the placebo effect. ${ }^{17-22}$ Two studies reference that a placebo and/or Hawthorne effect can be expected in randomized sham-controlled trials of interventions in populations with depression, anxiety, and PTSD because of the "intense nature of the intervention."17-22 Researchers in one study opined that participants, who were Marines, benefited from the study because they traveled to a resort town, and took leave from work. ${ }^{17,18,22}$ Another study detailed that it was not designed to evaluate components of a placebo response, including response expectancy, verbal suggestion, and stimulus conditioning. ${ }^{21}$ This placebo analysis demonstrates that although some of these components bearing on placebo were reported in the studies, no study described in the detail necessary to understand the influence on outcomes of any placebo response that may or may not have occurred.

\section{DISCUSSION}

What are the clinical and policy implications of the current evidence for $\mathrm{HBO}_{2}$ therapy in regard to TBI? To better understand these implications, a synthesis of the evidence was conducted by the SC and SMEs for each outcome category (see Table 2). Recommendations balance safety with efficacy of the procedure for a particular outcome. These recommendations are based solely on the presented systematic review results and are not to be construed as clinical practice guidelines in any way. Systematic review is the first step needed to make evidencebased informed decisions, but further key ingredients are necessary for a clinical practice guideline to be established.

\section{Synthesis of the evidence-mTBI populations}

Of the 3 SIGN 50 acceptable (+) studies involving a total 183 patients with mTBI suffering persistent symptoms, comparing $\mathrm{HBO}_{2}$ with sham, synthesis and analysis was conducted on cognitive, postconcussive symptom severity, and psychological outcomes. Two of the 3 studies report on adverse events. There seem to be infrequent adverse events and $\mathrm{HBO}_{2}$ appears to be safe for mTBI populations. However, given there are only 3 studies, safety is not well understood.

Although no statistically significant differences were noted across studies when comparing $\mathrm{HBO}_{2}$ with sham for the outcomes assessed, they did show a trend that patients improved over time within both the $\mathrm{HBO}_{2}$ and sham treatment groups. Effect sizes were not reported for any outcomes within the individual studies, and although validated tools were used, the sensitivity of these tools specific to TBI populations is questionable. Consensus was reached that further research is very unlikely 
TABLE 2 Quality assessment of the overall literature pool by outcome category ${ }^{a}$

\begin{tabular}{|c|c|c|c|c|}
\hline Treatment & $\begin{array}{l}\text { Number of } \\
\text { participants } \\
\text { completed } \\
\text { (number of } \\
\text { studies) }\end{array}$ & $\begin{array}{l}\text { Confidence in } \\
\text { estimate of } \\
\text { effect }^{\mathbf{b}}\end{array}$ & $\begin{array}{c}\text { Reported } \\
\text { studies safety } \\
\text { grade (number } \\
\text { of studies)/ } \\
\text { overall safety }^{c}\end{array}$ & $\begin{array}{l}\text { Strength of the } \\
\text { recommendation }^{\text {d }}\end{array}$ \\
\hline \multicolumn{5}{|l|}{ Mild TBI } \\
\hline \multicolumn{5}{|l|}{ Cognitive } \\
\hline $\mathrm{HBO}_{2}$ vs sham & $183(3)$ & A & $+2(2) / 0$ overall & $\begin{array}{l}\text { Weak recommendation } \\
\text { against }\end{array}$ \\
\hline $\begin{array}{l}\mathrm{HBO}_{2} \text { vs "standard } \\
\text { care" }\end{array}$ & $72(1)$ & B & $+2(1)$ & No recommendation \\
\hline \multicolumn{5}{|c|}{ Postconcussive symptom severity } \\
\hline $\mathrm{HBO}_{2}$ vs sham & $133(2)$ & A & $+2(1) / 0$ overall & $\begin{array}{l}\text { Weak recommendation } \\
\text { against }\end{array}$ \\
\hline $\begin{array}{l}\mathrm{HBO}_{2} \text { vs "standard } \\
\text { care" }\end{array}$ & $72(1)$ & B & $+2(1)$ & No recommendation \\
\hline \multicolumn{5}{|l|}{ Psychological } \\
\hline $\mathrm{HBO}_{2}$ vs sham & $183(3)$ & A & $+2(2) / 0$ overall & $\begin{array}{l}\text { Weak recommendation } \\
\text { against }\end{array}$ \\
\hline $\begin{array}{l}\mathrm{HBO}_{2} \text { vs "standard } \\
\text { care" }\end{array}$ & $72(1)$ & B & $+2(1)$ & No recommendation \\
\hline \multicolumn{5}{|l|}{ Moderate-to-severe TBI } \\
\hline \multicolumn{5}{|c|}{ Alterations in the level of consciousness } \\
\hline $\begin{array}{l}\mathrm{HBO}_{2} \text { vs "standard } \\
\text { care" }\end{array}$ & $219(4)$ & C & 0 & $\begin{array}{l}\text { Weak recommendation } \\
\text { in favor }\end{array}$ \\
\hline \multicolumn{5}{|l|}{ Intracranial pressure } \\
\hline $\begin{array}{l}\mathrm{HBO}_{2} \text { vs "standard } \\
\text { care" }\end{array}$ & $237(2)$ & B & 0 & No recommendation \\
\hline \multicolumn{5}{|c|}{ Glasgow Outcome Scale and mortality } \\
\hline $\begin{array}{l}\mathrm{HBO}_{2} \text { vs "standard } \\
\text { care" }\end{array}$ & $357(5)$ & C & 0 & $\begin{array}{l}\text { Weak recommendation } \\
\text { in favor }\end{array}$ \\
\hline
\end{tabular}

Abbreviations: $\mathrm{HBO}_{2}$, hyperbaric oxygen; TBI, traumatic brain injury.

aThis analysis usually also incorporates overall effect size according to outcomes; because of the heterogeneity among the studies and poor reporting, this was not done.

${ }^{b}$ Further research is very unlikely to change our confidence in the estimate of effect (A); further research is likely to have an important impact on our confidence in the estimate of effect and may change the estimate (B); further research is very likely to have an important impact on our confidence in the estimate of effect and is likely to change the estimate (C); any estimate of effect is very uncertain (D). 'Safety grade ranges from +2 appears safe with infrequent adverse events and interactions to -2 appears to have serious safety concerns that include frequent and serious adverse events and/or interactions.

dStrength of recommendation ranges from "strong recommendation in favor"-SME is very certain that benefits do outweigh risks and burdens-to "strong recommendation against"-SME is very certain that benefits do not outweigh the risks and burdens.

to change the team's confidence in the estimate of the effect. Given the evidence for $\mathrm{HBO}_{2}$ for patients with mTBI when compared with a sham intervention for cognition, postconcussive symptom severity, and psychological impairment, a weak recommendation against the use of $\mathrm{HBO}_{2}$ was reached at the expert roundtable. There does not appear to be added value of this therapy over and above the sham treatment, if in fact these are truly "sham" treatments.

Only one study compared $\mathrm{HBO}_{2}$ with "standard care" within the mTBI population. Highly powered, strong methodological studies with multiple comparator arms are needed to begin to draw conclusions to make recommendations in regard to the risk/benefit for $\mathrm{HBO}_{2}$ versus "standard care."

\section{Synthesis of the evidence-moderate-to-severe populations}

Of the 4 SIGN 50 acceptable (+) and 3 low (0) quality studies involving a total of 486 patients at the acute stage of moderate-to-severe TBI, synthesis and analysis was performed across alterations in the level of consciousness, GOS and mortality, and ICP where applicable, in comparison to no $\mathrm{HBO}_{2}$ treatment or some type of "standard care." The low (0) quality studies suffer from methodological flaws reported on by this systematic review, which leaves us to question the validity of the results being reported. Given the nature of these patients' condition, research becomes quite challenging. Many of these studies are also quite old dating

www.headtraumarehab.com 
to the early 1970s. Clinical approaches to neurotrauma have evolved greatly over the last 45 years. Only 3 of the 7 studies reported on adverse events. It was challenging to assess whether these adverse events occurred because of the nature of the population's condition or were caused by the intervention. The SC experts agreed safety is not well understood for $\mathrm{HBO}_{2}$ for moderateto-severe TBI populations.

Alterations in the level of consciousness were assessed in 4 studies, and the GOS and mortality were assessed in 5 studies. Given the mixed quality of these studies, the fact that many of the studies are quite old, and the sample sizes are relatively small, the SC experts agreed that for consciousness and mortality outcomes further research is very likely to have an important impact on the confidence in the estimate of the effect. Given the nature and severity of these patients' brain injuries, however, and noting that $\mathrm{HBO}_{2}$ does appear to improve patients' outcomes versus "standard care," the SC experts gave a weak recommendation in favor of $\mathrm{HBO}_{2}$ as compared with "standard care" for both consciousness and GOS/mortality. As discussed earlier, there was no one "standard of care" in these studies; because of this and the desperate need for interventions at the acute stage, the SC experts agreed that, if feasible and acceptable to the family and patient, it could be an option for consideration. Feasibility and acceptability will need to play a large role in the moderate-to-severe TBI populations once the methodological flaws are addressed in future studies.

ICP was assessed across 2 studies. The quality of the research and the results were mixed. The SC experts debated whether this outcome is clinically relevant to the purposes of this systematic review. No conclusion and recommendation was made.

\section{Addressing the placebo issue}

The scientific research community continues to test and debate specific and nonspecific effects of therapies in medicine on outcomes generally, and the placebo debate is no less important in the field of $\mathrm{HBO}_{2}$ for TBI. There exists an important debate of what constitutes a true sham for $\mathrm{HBO}_{2}$ therapy. ${ }^{63} \mathrm{~A}$ "true" sham may involve normal atmospheric pressure; all sham arms in the studies reviewed had some pressure over atmospheric for the sake of blinding. The shams utilized in $\mathrm{HBO}_{2}$ research require validation. Is it the oxygen, the pressure, or both making a difference in the actual intervention? Or are the effects specific only to the ritual being performed? If the ritual is the critical treatment element, can we enhance it safely at an affordable cost?

The placebo response is complex and is not unique to $\mathrm{HBO}_{2}$ studies in TBI. Acupuncture has been fiercely debated with mixed results from studies comparing real acupuncture to different shams. Is it the context and meaning of the intervention that is producing the effect? Is it worth investing in further research to uncover which parts of the therapeutic experience and what ritualistic components contribute to the efficacy/effectiveness of $\mathrm{HBO}_{2}$ for those suffering the consequences of TBI?

The placebo analysis conducted confirms that clinical ritualistic components of the therapy, actual and sham, are not being reported fully in the reviewed literature. The SC experts were not able to fully understand the meaning and contextual effects imparted by the encounter itself and concluded that a set of specific criteria for the creation of uniform reporting guidelines is necessary. The acupuncture research community developed Standards of Reporting Intervention of Clinical Trials in Acupuncture (STRICTA). ${ }^{64}$ Similarly, guidelines for conducting placebo-controlled clinical trials (STRICT-P) could enhance our understanding of how placebo components play a role in the interventions being investigated and what constitutes the most appropriate sham controls to use in future trials. This is a clear gap that needs further investigation in medicine at large, not only related to $\mathrm{HBO}_{2}$ and mTBI. A collaboration of placebo experts is required to push this forward. By reframing the concept of "placebo effects" into these components, we can begin to measure the meaning and contextual effects in clinical trials. The placebo components used in the placebo analysis reported here can be used as a building block for such standard reporting criteria development.

Aside from the challenge with placebo effects, the definition and criteria for diagnosing $\mathrm{mTBI}$ and moderateto-severe TBI is associated with a variety of symptoms and seems to be multidimensional. A holistic, patientcentered care approach should be considered to enhance patient response and improve well-being.

The following suggestions emerged:

1. Support placebo research to provide further insight on the specific and nonspecific effects of $\mathrm{HBO}_{2}$ on mTBI.

2. Investigate the effects of pressure and pressure changes to differentiate the specific pressure effects from the contextual nonspecific effects of pressure during sham treatments.

3. Explore the most validated and sensitive clinical outcome tools for mild and moderate-to-severe TBI therapy research to ensure consistent reporting and the availability of data for future study and consideration of meta-analysis.

4. Compare other types of interventions to $\mathrm{HBO}_{2}$ treatments for TBI. Even if placebo is the influential factor in mTBI therapeutic studies, direct head-to-head comparative effectiveness research and cost-benefit analyses comparing other modalities are necessary. 
5. Commission a network meta-analysis to evaluate all treatments for TBI, allowing for the assessment of the relative effectiveness of treatments when they have not been compared directly but have been compared with other treatments.

\section{CONCLUSIONS}

This systematic review revealed that for patients suffering from persistent symptoms after mTBI, $\mathrm{HBO}_{2}$ therapy is no better than sham treatment, if, in fact, the "sham" treatment is a true sham, and hence not recommended as a therapy. In comparison to "standard care," there is not enough evidence to draw conclusions at this time. However, the improvements in outcomes shown within groups for both $\mathrm{HBO}_{2}$ and sham treatment cannot be ignored. The ritual of the therapeutic encounter involved with $\mathrm{HBO}_{2} /$ sham $\mathrm{HBO}_{2}$ may be of therapeu- tic value to TBI. It is also possible another confounding specific effect has yet to be identified. We will not be able to answer questions about specific $\mathrm{HBO}_{2}$ attributes (inspired oxygen levels, pressure, dosing duration, frequency, and length), nonspecific placebo effects, and how to maximize therapeutic benefit for patients with $\mathrm{mTBI}$ at the lowest possible risk and cost without further research.

For moderate-to-severe TBI at the acute phase of treatment, although the methodology appears flawed across the studies, and specific outcomes may be unstable, because of the complexity and severity of brain injury in this population, $\mathrm{HBO}_{2}$ may be of value and could benefit these patients as a relatively safe adjunctive therapy if feasible and acceptable to the individual and family. Further research outlined in this report should be considered to resolve the controversy surrounding this field, but only if methodological flaws are avoided and bias minimized.

\section{REFERENCES}

1. Bennett MH, Trytko B, Jonker B. Hyperbaric oxygen therapy for the adjunctive treatment of traumatic brain injury. Cocbrane Database Syst Rev. 2012;12:Cd004609.

2. McDonagh M, Helfand M, Carson S, Russman BS. Hyperbaric oxygen therapy for traumatic brain injury: a systematic review of the evidence. Arch Phys Med Rehabil. 2004;85(7):1198-1204.

3. Alternative Therapy Evaluation Committee for the Insurance Corporation of British Columbia. A review of the scientific evidence on the treatment of traumatic brain injuries and strokes with hyperbaric oxygen. Brain Inj. 2003;17(3):225-236.

4. Hyperbaric Oxygen Therapy: Don't Be Misled. Food and Drug Administration. Consumer Health Information. Secondary Hyperbaric Oxygen Therapy: Don't Be Misled. http://www.fda.gov/ downloads/ForConsumers/ConsumerUpdates/UCM366015.pdf. Accessed February 15, 2015.

5. Rockswold SB, Rockswold GL, Zaun DA, Liu J. A prospective, randomized Phase II clinical trial to evaluate the effect of combined hyperbaric and normobaric hyperoxia on cerebral metabolism, intracranial pressure, oxygen toxicity, and clinical outcome in severe traumatic brain injury. J Neurosurg. 2013;118(6):1317-1328.

6. Management of Concussion/mTBI Working Group. VA/DoD Clinical Practice Guideline for Management of Concussion/Mild Traumatic Brain Injury. J Rehabil Res Dev. 2009;46(6):Cp1-68.

7. Weaver L; Undersea and Hyperbaric Medical Society. Hyperbaric Oxygen Therapy Indications. 13th ed. North Palm Beach, FL: Best Publishing Company; 2014.

8. Undersea and Hyperbaric Medical Society. Indications for hyperbaric oxygen therapy secondary indications for hyperbaric oxygen therapy. https://www.uhms.org/resources/hbo-indications.html. Accessed September 22, 2015.

9. Viera AJ, Garrett JM. Understanding interobserver agreement: the kappa statistic. Fam Med. 2005;37(5):360-363.

10. Scottish Intercollegiate Guidelines Network, SIGN. A Guideline Developer's Handbook. Secondary Scottish Intercollegiate Guidelines Network, SIGN. http://www.sign.ac.uk/methodology/ checklists.html. Accessed January 13, 2016.

11. Khorsan R, Crawford C. How to assess the external validity and model validity of therapeutic trials: a conceptual approach to sys- tematic review methodology. Evid Based Complement Alternat Med. 2014;2014:694804.

12. National Institute of Neurological Disorders and Stroke (NINDS) Common Data Elements. Secondary National Institute of Neurological Disorders and Stroke (NINDS) Common Data Elements. http://www.commondataelements.ninds.nih.gov. Accessed January 20, 2015.

13. Buckenmaier C, Crawford C, Lee C, Schoomaker E. Special issue: are active self-care complementary and integrative therapies effective for management of chronic pain? A rapid evidence assessment of the literature and recommendations for the field. Pain Med. 2014;15(S1):S1-S113.

14. Costello RB, Lentino CV, Boyd CC, et al. The effectiveness of melatonin for promoting healthy sleep: a rapid evidence assessment of the literature. Nutr J. 2014;13:106.

15. Lee C, Crawford C, Wallerstedt D, et al. The effectiveness of acupuncture research across components of the trauma spectrum response (TSR): a systematic review of reviews. Syst Rev. 2012;1:46.

16. Davidson J, Crawford C, Ives J, Jonas W. Homeopathic treatments in psychiatry: a systematic review of randomized placebo-controlled studies. J Clin Psychiatr. 2011;72(6): 795-805.

17. Cifu DX, Hart BB, West SL, Walker W, Carne W. The effect of hyperbaric oxygen on persistent postconcussion symptoms. J Head Trauma Rehabil. 2014;29(1):11-20.

18. Cifu DX, Walker WC, West SL, et al. Hyperbaric oxygen for blast-related postconcussion syndrome: three-month outcomes. Ann Neurol. 2014;75(2):277-286.

19. Wolf EG, Prye J, Michaelson R, et al. Hyperbaric side effects in a traumatic brain injury randomized clinical trial. Undersea Hyperb Med. 2012;39(6):1075-1082.

20. Wolf G, Cifu D, Baugh L, Carne W, Profenna L. The effect of hyperbaric oxygen on symptoms after mild traumatic brain injury. J Neurotrauma. 2012;29(17):2606-2612.

21. Miller RS, Weaver LK, Bahraini N, et al. Effects of hyperbaric oxygen on symptoms and quality of life among service members with persistent postconcussion symptoms: a randomized clinical trial. JAMA Intern Med. 2015;175(1):43-52. 
22. Cifu DX, Hoke KW, Wetzel PA, et al. Effects of hyperbaric oxygen on eye tracking abnormalities in males after mild traumatic brain injury. J Rehabil Res Dev. 2014;51(7):1047-1056.

23. Boussi-Gross R, Golan H, Fishlev G, et al. Hyperbaric oxygen therapy can improve postconcussion syndrome years after mild traumatic brain injury-randomized prospective trial. PLoS One. 2013;8(11):e79995.

24. Artru F, Chacornac R, Deleuze R. Hyperbaric oxygenation for severe head injuries. Preliminary results control study. Eur Neurol. 1976;14(4):310-318.

25. Rockswold GL, Ford SE, Anderson DC, Bergman TA, Sherman RE. Results of a prospective randomized trial for treatment of severely brain-injured patients with hyperbaric oxygen. J Neurosurg. 1992;76(6):929-934.

26. Lin JW, Tsai JT, Lee LM, et al. Effect of hyperbaric oxygen on patients with traumatic brain injury. Acta Neurochir Suppl. 2008; 101:145-149.

27. Ren H, Wang W, Ge Z, Zhang J. Clinical, brain electric earth map, endothelin and transcranial ultrasonic Doppler findings after hyperbaric oxygen treatment for severe brain injury. Chin Med J (Engl). 2001;114(4):387-390.

28. Rockswold SB, Rockswold GL, Zaun DA, et al. A prospective, randomized clinical trial to compare the effect of hyperbaric to normobaric hyperoxia on cerebral metabolism, intracranial pressure, and oxygen toxicity in severe traumatic brain injury. J Neurosurg. 2010;112(5):1080-1094.

29. Xie Z, Zhuang M, Lin L, et al. Changes of plasma C-reactive protein in patients with craniocerebral injury before and after hyperbaric oxygenation: a randomly controlled study. Neural Regen Res. 2007;2(5):314-317.

30. Rockswold GL, Ford SE. Preliminary results of a prospective randomized trial for treatment of severely brain-injured patients with hyperbaric oxygen. Minn Med. 1985;68(7):533-535.

31. Ren H, Wang W, Ge Z. Glasgow Coma Scale, brain electric activity mapping and Glasgow Outcome Scale after hyperbaric oxygen treatment of severe brain injury. Chin J Traumatol. 2001;4(4):239241.

32. Shi XY, Tang ZQ, Xiong B, et al. Cerebral perfusion SPECT imaging for assessment of the effect of hyperbaric oxygen therapy on patients with postbrain injury neural status. Chin J Traumatol. 2003;6(6):346-349.

33. Lee CH, Chen WC, Wu CI, Hsia TC. Tension pneumocephalus: a rare complication after hyperbaric oxygen therapy. Am J Emerg Med. 2009;27(2):257.e1-e3.

34. Lee LC, Lieu FK, Chen YH, Hung TH, Chen SF. Tension pneumocephalus as a complication of hyperbaric oxygen therapy in a patient with chronic traumatic brain injury. Am J Phys Med Rebabil. 2012;91(6):528-532.

35. Sukoff MH, Ragatz RE. Hyperbaric oxygenation for the treatment of acute cerebral edema. Neurosurgery. 1982;10(1):29-38.

36. Barrett KF, Masel B, Patterson J, et al. Regional CBF in chronic stable TBI treated with hyperbaric oxygen. Undersea Hyperb Med. 2004;31(4):395-406.

37. Churchill S, Weaver LK, Deru K, et al. A prospective trial of hyperbaric oxygen for chronic sequelae after brain injury (HYBOBI). Undersea Hyperb Med. 2013;40(2):165-193.

38. Giebfried JW, Lawson W, Biller HF. Complications of hyperbaric oxygen in the treatment of head and neck disease. Otolaryngol Head Neck Surg. 1986;94(4):508-512.

39. Gossett WA, Rockswold GL, Rockswold SB, et al. The safe treatment, monitoring and management of severe traumatic brain injury patients in a monoplace chamber. Undersea Hyperb Med. 2010;37(1):35-48.

40. Harch PG, Andrews SR, Fogarty EF, et al. A phase I study of low-pressure hyperbaric oxygen therapy for blast-induced post- concussion syndrome and posttraumatic stress disorder. J Neurotrauma. 2012;29(1):168-185.

41. Mogami H, Hayakawa T, Kanai N, et al. Clinical application of hyperbaric oxygenation in the treatment of acute cerebral damage. J Neurosurg. 1969;31(6):636-643.

42. Hayakawa T, Kanai N, Kuroda R, Yamada R, Mogami H. Response of cereborspinal fluid pressure to hyperbaric oxygenation. J Neurol Neurosurg Psychiatr. 1971;34(5):580-586.

43. Holbach KH, Schroder FK, Datene G, Dohr H. Hyperbaric oxygenation: a treatment in neurosurgery. J Neurol Neurosurg Psychiatr. 1970;33(5):717.

44. Holbach KH, Schroder FK, Koster S. Alterations of cerebral metabolism in cases with acute brain injuries during spontaneous respiration of air, oxygen and hyperbaric oxygen. Eur Neurol. 1972;8(1):158-160.

45. Nakamura T, Kuroda Y, Yamashita S, et al. Hyperbaric oxygen therapy for consciousness disturbance following head injury in subacute phase. Acta Neurochir Suppl. 2008;102:21-24.

46. Rockswold SB, Rockswold GL, Vargo JM, et al. Effects of hyperbaric oxygenation therapy on cerebral metabolism and intracranial pressure in severely brain injured patients. J Neurosurg. 2001;94(3):403-411.

47. Shi XY, Tang ZQ, Sun D, He XJ. Evaluation of hyperbaric oxygen treatment of neuropsychiatric disorders following traumatic brain injury. Chin Med J (Engl). 2006;119(23):1978-1982.

48. Holbach KH, Caroli A, Wassmann H. Cerebral energy metabolism in patients with brain lesions of normo- and hyperbaric oxygen pressures. J Neurol. 1977;217(1):17-30.

49. Sahni T, Jain M, Prasad R, Sogani SK, Singh VP. Use of hyperbaric oxygen in traumatic brain injury: retrospective analysis of data of 20 patients treated at a tertiary care centre. $\mathrm{Br} J$ Neurosurg. 2012;26(2):202-207.

50. Myers RA, Baker T, Cowley RA. Hyperbaric medicine: state of the art, 1979. Am Surg. 1982;48(9):487-494.

51. Brown JA, Preul MC, Taha A. Hyperbaric oxygen in the treatment of elevated intracranial pressure after head injury. Pediatr Neurosci. 1988;14(6):286-290.

52. Hardy P, Johnston KM, DeBeaumont L, et al. Pilot case study of the therapeutic potential of hyperbaric oxygen therapy on chronic brain injury. J Neurol Sci. 2007;253(1-2):94-105.

53. Neubauer RA, Gottlieb SF, Pevsner NH. Hyperbaric oxygen for treatment of closed-head injury. South Med J. 1994;87(9): 933-936.

54. Woolley SM, Lawrence JA, Hornyak J. The effect of hyperbaric oxygen treatment on postural stability and gait of a brain injured patient: single case study. Pediatr Rebabil. 1999;3(3):81-90.

55. Wright JK, Zant E, Groom K, Schlegel RE, Gilliland K. Case report: treatment of mild traumatic brain injury with hyperbaric oxygen. Undersea Hyperb Med. 2009;36(6):391-399.

56. Artru F, Philippon B, Gau F, Berger M, Deleuze R. Cerebral blood flow, cerebral metabolism and cerebrospinal fluid biochemistry in brain-injured patients after exposure to hyperbaric oxygen. Eur Neurol. 1976;14(5):351-364.

57. Hollin SA, Espinosa OE, Sukoff MH, Jacobson JH, 2nd. The effect of hyperbaric oxygenation on cerebrospinal fluid oxygen. J Neurosurg. 1968;29(3):229-235.

58. Lv LQ, Hou LJ, Yu MK, et al. Hyperbaric oxygen therapy in the management of paroxysmal sympathetic hyperactivity after severe traumatic brain injury: a report of 6 cases. Arch Phys Med Rehabil. 2011;92(9):1515-1518.

59. Mitani M. Brain “implications for $\mathrm{HBO}_{2}$ ”. Undersea Hyperb Med. 2004;31(1):163-166.

60. Weaver LK, Cifu D, Hart B, Wolf G, Miller S. Hyperbaric oxygen for postconcussion syndrome: design of Department of Defense clinical trials. Undersea Hyperb Med. 2012;39(4):807-814. 
61. Jonas WB. Reframing placebo in research and practice. Philos Trans R Soc Lond B Biol Sci. 2011;366(1572):18961904.

62. Bergmann JF, Chassany O, Gandiol J, et al. A randomised clinical trial of the effect of informed consent on the analgesic activity of placebo and naproxen in cancer pain. Clin Trials Metaanal. 1994;29(1):41-47.
63. Harch PG. Hyperbaric oxygen therapy for postconcussion syndrome: contradictory conclusions from a study mischaracterized as sham-controlled. J Neurotrauma. 2013;30(23):1995-1999.

64. MacPherson H, Altman DG, Hammerschlag R, et al. Revised standards for reporting interventions in clinical trials of acupuncture (STRICTA): Extending the CONSORT statement. J Evid Based Med. 2010;3(3):140-155. 